\title{
- Simple scaling of catastrophic landslide dynamics
}

3 One-sentence summary: We show how the bulk dynamics of catastrophic landslides are fun-

4 damentally set by their rupture length scale though inverse modeling of teleseismic waveforms

5 calibrated by satellite imagery.

\section{post-review version}


Catastrophic landslides involve the acceleration and deceleration of millions of tons of rock and debris in response to the forces of gravity and dissipation. Their unpredictability and frequent location in remote areas have made observations of their dynamics rare. Through real-time detection and inverse modeling of teleseismic data we show that landslide dynamics are primarily determined by the length scale of the source mass. When combined with geometric constraints from satellite imagery, the seismically determined landslide force histories yield estimates of landslide duration, momenta, potential energy loss, mass, and runout trajectory. Measurements of these dynamical properties for 29 teleseismogenic landslides are consistent with a simple acceleration model in which height drop and rupture depth scale with the length of the failing slope. 
Seismic radiation from landslides is broadband and complex (1). Short-period waves result from the myriad momentum exchanges taking place within the granular mass and along its sliding boundary. They are distributed in time and low in amplitude compared with the impulsive radiation associated with the sudden stress drop in tectonic earthquakes. Long-period waves radiated by landslides are simpler: they are generated by the broad cycle of unloading and reloading of the solid Earth (2-4) induced by the bulk acceleration and deceleration of the landslide mass. The corresponding momentum exchange is complicated by entrainment and deposition (5-7) during motion and by topographic undulations along the slide path (8). Characteristic unloading-reloading times in large landslides are several tens of seconds, making them efficient sources of seismic waves at periods of that order (9).

Traditional earthquake monitoring conducted by national and international agencies is designed for detection of impulsive short-period seismic waves and for location of associated tectonic earthquakes and explosions. Landslide detections are rare. A complementary method based on near-real-time data from the Global Seismographic Network (GSN) allows for the detection of seismic events through continuous back-projection of the long-period wavefield (10-12). This event-detection algorithm detects $>90 \%$ of $M \geq 5.0$ shallow earthquakes reported by other agencies, and identifies about ten events each month that are not in other seismicity catalogues. Some of these unassociated events have been correlated with large-scale glacier calving $(13,14)$ and volcanic unrest $(15)$. Here we identify and investigate another subset of these events associated with catastrophic (large and fast) landslides.

The event-detection algorithm locates events with an initial accuracy of $20-100 \mathrm{~km} \mathrm{(10).}$ A terrestrial landslide source is established by combining this geographic location with satellite imagery, field photographs, news reports, local seismic recordings, and other sources. A comprehensive investigation of 195 unassociated detections for 2010 led to the identification of eleven major landslides (Table S1, Events 16-26). All of the seismically detected landslides 
generated long-period surface waves roughly equivalent to a magnitude $M_{\mathrm{SW}} \sim 5$ tectonic earthquake and all were recorded at multiple seismographic stations. Tectonically generated surfacewave signals of this magnitude are routinely used to determine earthquake fault geometries and seismic moments (16), suggesting that similar methods could also be used to provide a quantitative characterization of the detected landslides. For example, Kanamori and co-workers $(17,18)$ measured a subhorizontal force of $\sim 150$ s duration and maximum amplitude $\sim 10^{13} \mathrm{~N}$ associated with the massive debris avalanche following the 1980 eruption of Mount St. Helens volcano (Table S1). Seismological analyses of long-period data have usually focused on single landslide events, and typically have been limited to estimation of the average slide direction (often only in the horizontal), peak force, and duration of sliding (19-22). Field observations, on the other hand, frequently suggest complex three-dimensional (3-D) landslide trajectories, and numerical modeling has highlighted the effects of such complexity on the radiated seismic waves $(7,8)$.

We developed an inverse method (12) to infer the 3-D force sequence generated by bulk landslide motion (23) - from which we can deduce the trajectory of slip and dynamic properties. The new algorithm builds on and extends established methods used in earthquake analysis $(12,16)$. When applied to one of the largest landslides of 2010, this approach results in a first-order characterization of the event (Fig. 1). On January 4 of that year, our algorithm $(10,11)$ automatically detected a seismic event of long-period magnitude $M_{\mathrm{SW}} \approx 5.3$ at 08:36 GMT and roughly located the source in northern Pakistan (Table S1). None of the international earthquake-monitoring agencies ISC, IDC, or NEIC reported this event. Following anecdotal reports that a major landslide had struck the village of Attabad that morning — blocking the Karakoram Highway, damming the Hunza river, and causing several fatalities (24) we inspected long-period waveform data recorded on proximal stations and established that the seismic signal was likely caused by the Attabad slope failure. This association was confirmed by our inverse model, which provided a more accurate source location within $15 \mathrm{~km}$ of Attabad 
and which pointed to a direction of motion down to the SSW, consistent with local reports. These reports also indicated a time of failure consistent with the seismic detection.

The estimated time sequence of forces induced by acceleration of the Hunza-Attabad landslide indicates a roughly sinusoidal sequence lasting $\Delta t \sim 60 \mathrm{~s}$ (Fig. 1a). The 3-D force vector components vary in a synchronous fashion, which suggests a consistent azimuth of acceleration and deceleration and therefore a linear runout. During the first $25 \mathrm{~s}$ the force vector points consistently to the NNE with an upward vertical component, indicating reaction to acceleration of the slide mass downhill in the SSW direction. The subsequent time series reflects reversal of the force vector during deceleration, as the slide mass approached the bottom of the valley.

Because the negated force history is equivalent to the rate of change of bulk landslide momentum over time (23), its integration gives the bulk momentum over time $\mathbf{p}(t)=(m \mathbf{v})(t)$. This time series is constrained to be stationary during inversion. Assuming a constant bulk mass $m$ over time, further integration gives the mass-scaled, 3-D vector trajectory of motion $m \mathbf{D}(t)$. If an independent measure of landslide volume or mass $m$ is available, we can divide by $m$ to obtain the 3-D runout $\mathbf{D}(t)$ and compare it against terrain data and post-failure imagery to test the validity of the inversion results and the assumption of constant mass. Alternatively, we can estimate the bulk landslide mass by comparing the mass-scaled maximum horizontal displacement $m D_{\mathrm{h}}$ with a center-of-mass displacement estimated from terrain data and imagery. Using the second approach, illustrated in satellite imagery of Hunza-Attabad (Fig. 1c), we estimated a horizontal center-of-mass displacement of $940 \mathrm{~m}$, which gave a mass of $m \approx 1.4 \times 10^{11} \mathrm{~kg}$ and the runout path $\mathbf{D}(t)$ shown in Fig. 1b. Evaluation in the field has estimated the deposited volume at $\sim 45$ million $\mathrm{m}^{3}(24)$. Assuming a debris density of $2400 \mathrm{~kg} \mathrm{~m}^{-3}$, this suggests a source mass of $\sim 1.1 \times 10^{11} \mathrm{~kg}$, broadly consistent with our estimate.

We applied the technique of landslide seismic detection and source inversion to a total of 29 
events spanning 1980-2012 (Table S1). This set includes the three largest landslides of the last 33 years: Mount St. Helens in 1980 (Table S1), Kaiapit in 1988 (25), and Yìgòng in 2000 (26). Of these 29 events, 27 were recorded on global network stations while the two smallest — at Fāngtúnshān/Tàimālǐ in Taiwan (27) in 2009 and Akatani in Japan (28) in 2011 — were well recorded on regional networks. By analyzing all 29 landslides in a methodologically consistent fashion, we generated empirical constraints on catastrophic landslide dynamics spanning three orders of magnitude of failure mass that can be used with confidence in analyses of scaling (Table S1; Fig. 3).

A practical result is the logarithmic relationship (Fig. 3a) we see between the long-period magnitude $M_{\mathrm{SW}}$ and the maximum force $F_{\max }$. The magnitude estimates span $M_{\mathrm{SW}} \approx 4.6-5.6$ and are available only for the 27 global detections. The maximum forces here span $F_{\max } \approx$ $4 \times 10^{10}-5 \times 10^{12} \mathrm{~N}$ and are typically associated with the acceleration phase of the landslide. The correlation is strong, suggesting that the maximum force can be estimated from the longperiod magnitude alone (to within a factor of two) and prior to waveform modeling.

We find a consistent pattern of scaling (Fig. 3b-f) among the inferred dynamic properties that can be explained with a very simple model of slope collapse and acceleration in which a single length scale $L$ determines all the geometrical properties of the landslide source and its acceleration phase (12). The simple model and the inversion results indicate a linear dependence of landslide mass on maximum force $m \approx 0.54 F_{\max }$ (Fig. 3b). They indicate no scaling dependence, but much variability (Fig. 3d), for peak acceleration $a \approx 2 \mathrm{~m} \mathrm{~s}^{-2}$. Observed scaling dependencies on maximum force match model deductions: peak momentum is $p_{\max } \approx 27 F_{\max }^{7 / 6}$ (Fig. 3c), potential energy loss is $\Delta E \approx 3.8 F_{\max }^{4 / 3}$ (Fig. 3e), and runout duration is $\Delta t \approx 127 F_{\max }^{1 / 6}$. Similarly, we find dependencies on potential energy loss such as $\Delta t \approx 110 \Delta E^{1 / 8}$ (Fig. 3f) and $p_{\max } \approx 10 \Delta E^{7 / 8}$ that accord with the model. Together our results indicate peak kinetic energy is on average about $24 \%$ of potential energy loss. A practical outcome is that the mass-force 
relation can be combined with the observed scaling between magnitude and force to provide an approximate means of estimating landslide mass (in $10^{12} \mathrm{~kg}$ ) from long-period magnitude alone as $m \approx 0.54 \times 10^{2.2 M_{\mathrm{SW}}-12}$

Runout duration $\Delta t$ and trajectory $\mathbf{D}(t)$ inferred seismically reflect the phase of major height drop and thus significant force. For some landslides however, particularly for those running onto and down glaciers (such as Mt. Garmo (29) in 2001 and Mt. Lituya in 2012), a second longer phase of low gradient, likely low deceleration runout was mapped on imagery, but not recorded in the long-period seismicity. Such long-runout events likely indicate unusually low rates of energy dissipation as a result of frictional melting of glacial ice.

The most notable, previously undocumented landslides we identified are the seven catastrophic $\left(M_{\mathrm{SW}}\right.$ 4.6-5.4; Table S1) events detected over four days in September 2010 and located in the eastern Karakoram. All exhibited the seismic characteristics of landslides and none were detected by earthquake monitoring agencies. Our inversions of these events indicate a common runout direction of W-WSW for all the failures, and analysis of multitemporal Landsat imagery (Fig. 2c) identified only one candidate slope failure, collapsing onto the Siachen Glacier, consistent with this time window and geographic location. Subsequent mapping using multitemporal GeoEye imagery (Fig. 2a,b) confirmed multiple failures of the northern flank of the valley.

Unlike the Mt Garmo and Mt Lituya events, runout over the Siachen glacier surface was relatively short and comparable to the height drop. Using the GeoEye imagery we estimated runout for the largest event at $D_{\mathrm{h}} \approx 1320 \mathrm{~m}$ and deduce the failure mass at around $m \approx 1.9 \times$ $10^{11} \mathrm{~kg}$ and maximum acceleration of $2.2 \mathrm{~m} \mathrm{~s}^{-2}$. Because the other six events could not be tied to runout patterns in the imagery, we assumed the same maximum acceleration to calibrate their LFH inversions, yielding estimates of failure masses ranging from $m \approx 1.1 \times 10^{10} \mathrm{~kg}-$ $1.4 \times 10^{11} \mathrm{~kg}$. 
This sequence of massive landsliding is an example of progressive slope failure involving multiple collapses of bedrock volumes each exceeding $10^{6}-10^{7} \mathrm{~m}^{3}$. While it is recognized that episodes of massive mass-wasting often comprise a hierarchy of individual landslide events, repeated similar-scale failures of the same mountain slope over mere days are more difficult to explain. In our catalogue of inversions, only the paired Randa events (30) in 1991 involve closely repeated failure of a similar scale at the same location. Were it not for the seismic detection, force inversion and satellite-image mapping employed here, the Siachen Glacier landslide deposit would likely be falsely interpreted as the composite of one or two extremely large failures. What is more, given its remote location it would likely have gone undetected for some time. 


\section{References}

1. D. Weichert, R. B. Horner, S. G. Evans, Bulletin of the Seismological Society of America 84, 1523 (1994).

2. Y. Takei, M. Kumazawa, Geophysical Journal International 121, 641 (1994).

3. Y. Fukao, Geophysical Journal International 122, 243 (1995).

4. M. J. McSaveney, G. Downes, Landslides, J. Rybar, J. Stemberk, P. Wagner, eds. (Balkema, Lisse, 2002), pp. 649-654.

5. G. B. Crosta, H. Chen, C. F. Lee, Geomorphology 60, 127 (2004).

6. S. N. Ward, S. Day, Geophysical Journal International 167, 991 (2006).

7. L. Moretti, et al., Geophys. Res. Lett. 39, L16402 (2012).

8. P. Favreau, A. Mangeney, A. Lucas, G. Crosta, F. Bouchut, Geophysical Research Letters 37, L15305 (2010).

9. E. A. Okal, J. Phys. Earth 38, 445 (1990).

10. G. Ekström, Bull. Seism. Soc. Am. 96, 1201 (2006).

11. G. Ekström, M. Nettles, Global CMT catalog (2012). 〈http://globalcmt.org>.

12. See supplementary materials on Science Online.

13. G. Ekström, M. Nettles, G. A. Abers, Science 302, 622 (2003).

14. M. Nettles, G. Ekström, Ann. Rev. Earth Planet. Sci. 38, 467 (2010).

15. A. Shuler, G. Ekström, J. Volc. Geothermal Res. 181, 219 (2009). 
16. G. Ekström, M. Nettles, A. M. Dziewonski, Phys. Earth Planet. Int. 200-201, 1 (2012).

17. H. Kanamori, J. W. Given, Journal of Geophysical Research 87, 5422 (1982).

18. H. Kanamori, J. W. Given, T. Lay, Journal of Geophysical Research 89, 1856 (1984).

19. H. S. Hasegawa, H. Kanamori, Bulletin of the Seismological Society of America 77, 1984 (1987).

20. E. E. Brodsky, E. Gordeev, H. Kanamori, Geophysical Research Letters 30, 2236 (2003).

21. M. La Rocca, et al., Bulletin of the Seismological Society of America 94, 1850 (2004).

22. N. A. Pino, M. Ripepe, G. B. Cimini, Geophysical Research Letters 31, L02605 (2004).

23. W. G. Pariseau, Engineering Geology 16, 111 (1980).

24. D. Petley, International Water Power \& Dam Construction 63, 27(3) (2011).

25. M. Peart, Quarterly Journal of Engineering Geology 24, 399 (1991).

26. Y.-J. Shang, et al., Geomorphology 54, 225 (2003).

27. C.-H. Lin, H. Kumagai, M. Ando, T.-C. Shin, Geophysical Research Letters 37, L22309 (2010).

28. M. Yamada, Y. Matsushi, M. Chigira, J. Mori, Geophysical Research Letters 39, L13301 (2012).

29. V. M. Kotlyakov, et al., Materialy Gliatsiologicheskikh Issledovanii 95, 221 (2003).

30. E. Eberhardt, D. Stead, J. S. Coggan, International Journal of Rock Mechanics and Mining Sciences 41, 69 (2004). 


\section{Acknowledgments}

We are grateful to C.-W. Lin, R.-J. Rau, S.-P. Lee, Hongey Chen, S.-H. Liu and Y.-C. Tsang for help with analysis of landslides triggered by Typhoon Morakot, to E. Choi and M. Reitz for discussions on landslide mechanics, and to D. Petley for help and information on several of the landslide events reported here. Data are available in the Suppmentary Materials. This research was supported by National Science Foundation Awards EAR-1150072 and EAR-1227083. 
Figure 1: Landslide force history and trajectory for the Hunza-Attabad landslide. (a) Inversion of the landslide force history $\mathbf{F}(t)$ (LFH) of this event, pinning the time of main failure at 08:37UT (Table S1); (b) The planform trajectory of landslide motion deduced by doubly integrating the LFH and scaling by the runout distance mapped in (c). (c) Satellite-image mapping of the landslide scar and runout. The estimated centers of the source ('src') and deposits ('dpo') are indicated; their spatial separation was used to estimate $D_{\mathrm{h}}$, determine the effective mass, and scale the displacement trajectory $\mathbf{D}(t)$.

Figure 2: Siachen landslides, September 2010. (a) Pre- and (b) post-event GeoEye $50 \mathrm{~cm}$-resolution VNIR imagery of Siachen Glacier landslide complex. (c) Inferred trajectories for the seven Siachen landslides. The slide origins were chosen to coincide, in order to illustrate the good agreement in average slide direction, with some variablility in motion in the lower portions of the trajectories. Outlined in green and yellow are the approximate source and deposit areas, respectively.

Figure 3: Maximum force $F_{\max }$ versus (a) long-period surface-wave magnitude $M_{\mathrm{SW}}$, (b) mass $m$, (c) maximum momentum $p_{\max }$, (d) maximum acceleration $a_{\max }$, and (e) potential energy loss $\Delta E$. Runout duration $\Delta t$ versus potential energy loss $\Delta E$ is shown in (f). In (a)-(c), (e), and (f), the solid lines show model fits and the dashed lines indicate model mean confidence intervals at the $99 \%$ level. 

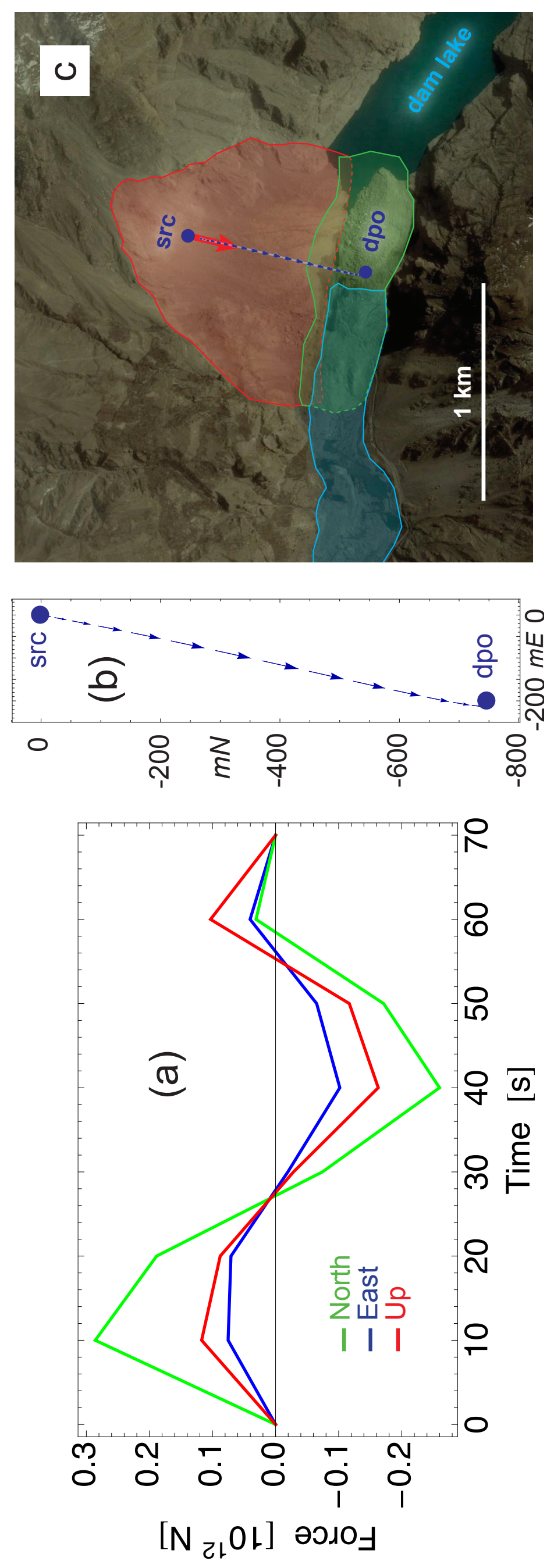


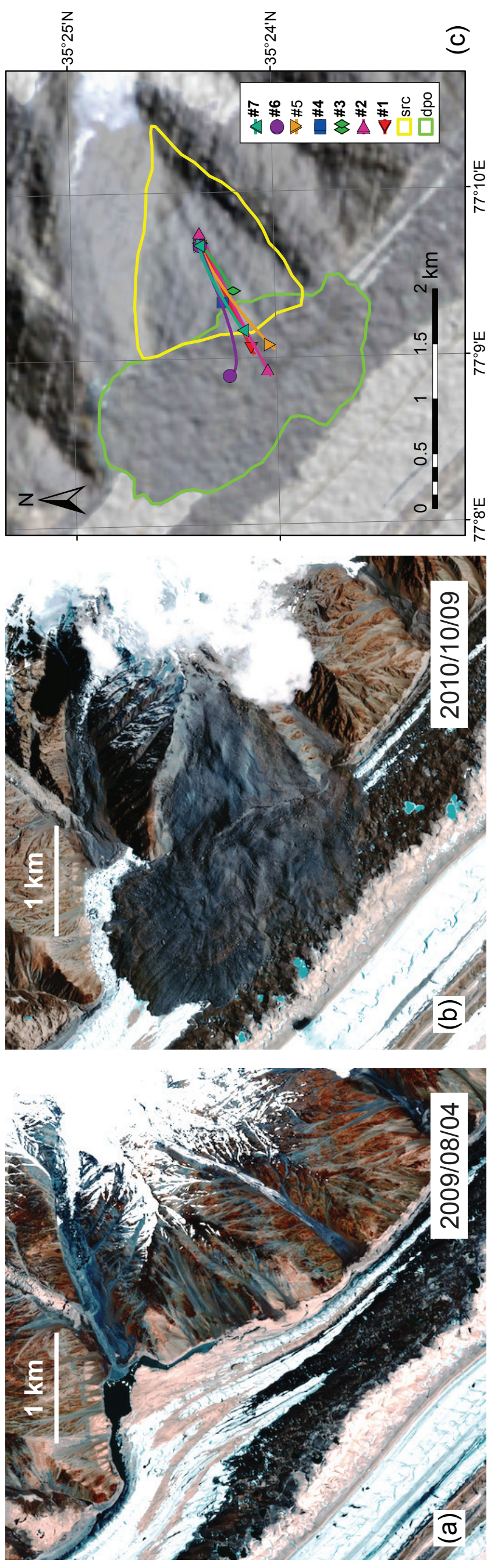



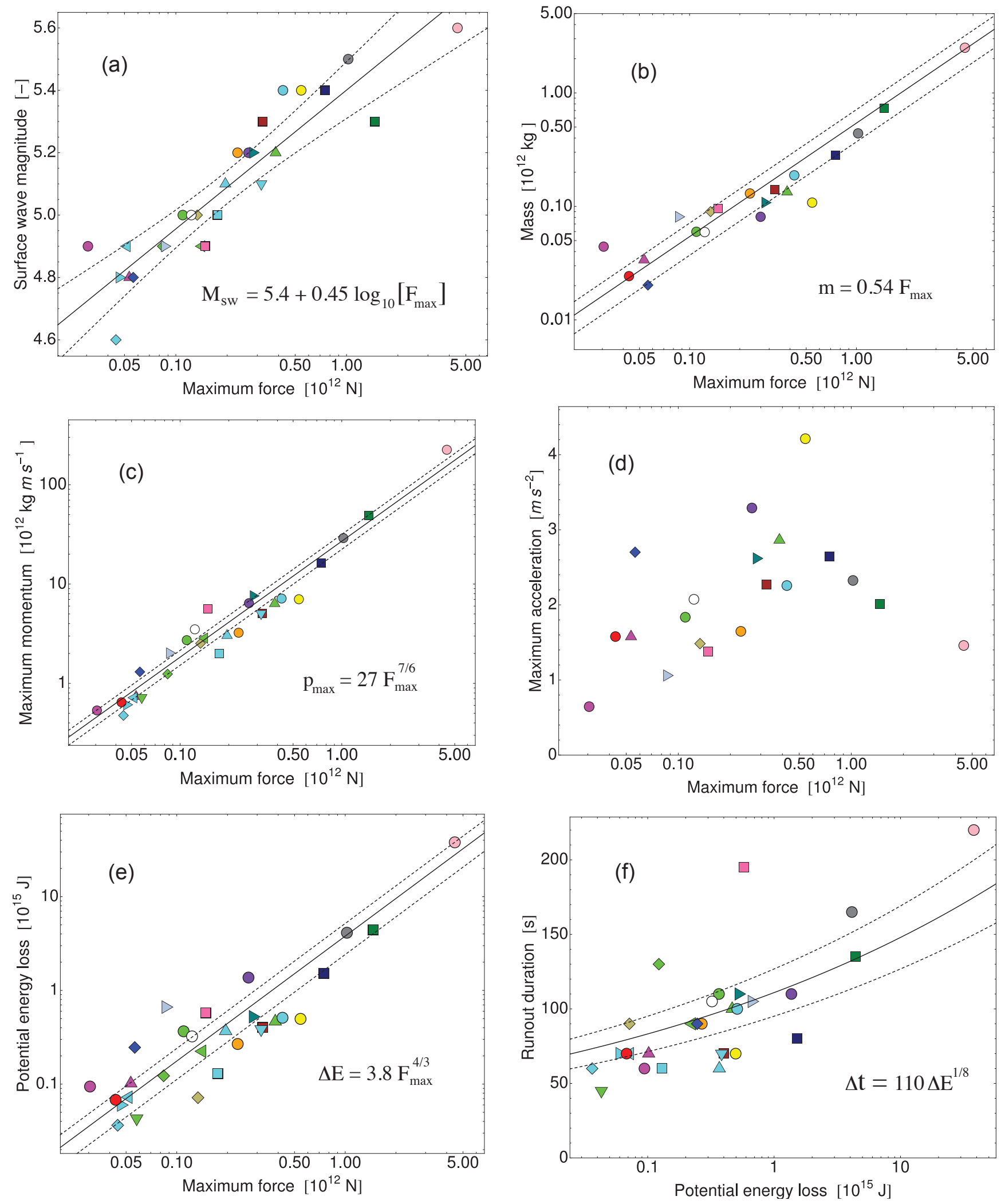

$\begin{array}{cc}\bigcirc & \text { Valpola } \\ \square & \text { Kaiapit } \\ & \text { Randa \#1 } \\ \triangle & \text { Randa \#2 } \\ & \text { Conchut } \\ & \text { Yigong } \\ \square & \text { Mt Garmo } \\ \square & \text { Mt Steller } \\ & \text { Mt Steele } \\ \triangle & \text { Hsiaolin } \\ \triangle & \text { Taoyuan }\end{array}$

$\triangle \quad$ Fangtunshan \#2

\section{Fuxing}

Hunza-Attabad

- Rio Socota

D Sheemahant

$\square \quad$ Mt Meager

$\triangleleft \quad$ Siachen \#1

D Siachen \#2

$\diamond \quad$ Siachen \#3

$\square \quad$ Siachen \#4

$\nabla$

Siachen \#5

Siachen \#6

Siachen \#7

Akatani

$\bigcirc$ Seti-Annapurna

$\checkmark \quad$ Mt Lituya 


\section{Supplementary Materials for}

\section{Simple Scaling of Catastrophic Landslide Dynamics}

Göran Ekström and Colin P. Stark

4 correspondence to: ekstrom@1deo.columbia.edu or cstark@ldeo.columbia.edu

$5 \quad$ This PDF file includes:

$6 \quad$ Materials and Methods

7 Supplementary Text

$8 \quad$ Figure $\mathrm{S} 1$

9 Table $\mathrm{S} 1$

10 References and Notes 


\section{Materials and Methods}

\section{Event Detection and Location}

Detection and location of seismic events that emit teleseismically detectable long-period seismic waves is accomplished using the algorithm described by Ekström et al. (10). The initial analysis makes use of seismograms collected from global networks in near-real time, and automatic results are posted on the Global CMT web site (11). Subsequent analysis makes use of additional archived data: typically data from 100-200 stations are included. Signals are analyzed for detections in the period band $35-150 \mathrm{~s}$. The algorithm is based on a grid search of potential event locations on the surface of the Earth. For each location, the Rayleigh wave dispersion is calculated to each station. To account for the geographic heterogeneity of surface-wave phase velocities, the dispersion correction is calculated from global phase-velocity maps (31). The recorded signals are back-propagated to the test location by deconvolution of the propagation dispersion. The processed signals are analyzed for the simultaneous presence of coherent energy at several stations, and empirically established criteria are used to declare an event detection (10). A comparison based on locations of known earthquakes from the NEIC catalog shows that the surface-wave locations have median deviations from the NEIC locations of approximately $40 \mathrm{~km}(10)$. The magnitude $M_{\mathrm{SW}}$ of the detected event is calculated from the amplitude $A$ of the long-period surface waves using the expression $M_{\mathrm{SW}}=c+\frac{2}{3} \log A$. The calibration factor $c$ is determined by regression using shallow earthquakes with known moment magnitudes (10).

\section{Landslide Force Inversion}

The seismic waves generated by a landslide source are caused by time-varying forces acting on the Earth. We follow the approach developed by Kanamori et al. (18) and consider the sliding mass a separate body from the solid Earth. The momentum change of the slide is equivalent to a force $\mathbf{F}_{\mathrm{S}}=\mathrm{d}(m \mathbf{v}) / \mathrm{d} t$, where $m$ is the mass of the slide and $\mathbf{v}$ is the velocity of the slide. The forces acting on the slide mass are gravity, friction, and centripetal forces, and each of these has a reactive counterpart acting on the solid earth in an opposite direction. The landslide therefore exerts a force on the solid Earth

$$
\mathbf{F}[\mathbf{x}, t]=-\mathbf{F}_{\mathrm{S}}=-\frac{\mathrm{d}(m \mathbf{v})}{\mathrm{d} t}[\mathbf{x}, t] .
$$

In simple terms, as the landslide mass accelerates and then decelerates down slope it effectively unloads and then reloads the hillslope, and this variable loading of the elastic solid Earth generates seismic waves.

In practice we cannot resolve the spatial distribution of the force and we parameterize $\mathbf{F}$ as a bulk-average, time-varying point force acting on the Earth's surface. This is justified to the extent that the spatial scale of the slide is small compared with the wavelength of the seismic waves and with the distances to the recording seismic stations. The seismic radiation from the torque exerted by the slide mass is weak for the type of seismic waves considered here (20), 
and we do not include this contribution to the landslide seismograms. Analysis is restricted to long-period waves with $T \geq 30 \mathrm{~s}$ since the unloading/loading cycle, i.e., the duration of slip, is of that order (Table S2), such that the bulk of the seismic wave energy is radiated at long periods.

We parameterize the time-varying force as a sequence of partially overlapping isosceles triangles with a half-width appropriate for resolving the complexity seen in the seismograms - typically 10 to $15 \mathrm{~s}$. Synthetic seismograms are calculated by summation of the Earth's elastic normal modes using the PREM Earth model (32) and corrections for Earth's laterally heterogeneous crust and mantle (16). We solve for the amplitudes of the triangles that define the time histories of each component of the force (up, north, east) by minimizing, in a least-squares sense, the misfit between observed and corresponding synthetic seismograms. The time history of each force component is constrained to integrate to zero to satisfy the physical condition that the sliding mass is at rest before and after the landslide. A weak smoothness constraint is also applied, which eliminates rapid oscillations in the force-time histories. We also solve for the best-fit point-source location of the landslide source. Inversion for the force parameters is performed using a modified version of the centroid-moment-tensor (CMT) algorithm (33).

An example of the data used and the match between observed and model seismograms for the Hunza-Attabad landslide (24) (Table S1) is shown in Figure S1. The closest station used in the analysis was KBL in Kabul, Afghanistan at a distance of $\sim 600 \mathrm{~km}$. The GSN station in Nilore, Pakistan was not operating at the time of the landslide.

The relationship between the estimated forces on the Earth and the dynamic parameters of the slide mass is written

$$
\mathbf{I}[t]=-(m \mathbf{v})[t]=\int_{0}^{t} \mathbf{F}[\tau] \mathrm{d} \tau
$$

where $\mathbf{I}[t]$ is the impulse acting on the Earth and $-(m \mathbf{v})[t]$ is the momentum of the slide mass. Integrating the force a second time, we obtain an expression for the trajectory, which, if a fixed reference slide mass $m_{0}$ is chosen, can be written

$$
\mathbf{D}[t]=-\frac{1}{m_{0}} \int_{0}^{t} \mathbf{I}[\tau] \mathrm{d} \tau
$$

where $\mathbf{D}[t]$ is the time-varying displacement of the center of mass.

The trade-off that exists between mass and displacement in this point-source representation is apparent. However, if the final displacement $\mathbf{D}[t \rightarrow \infty]$ of the sliding mass is known from independent observations, the equation shows that a representative slide mass can be estimated from the seismically determined forces (Table S1). Alternatively, if the slide mass is known, the acceleration, speed, and slide trajectory can be determined from the forces. 

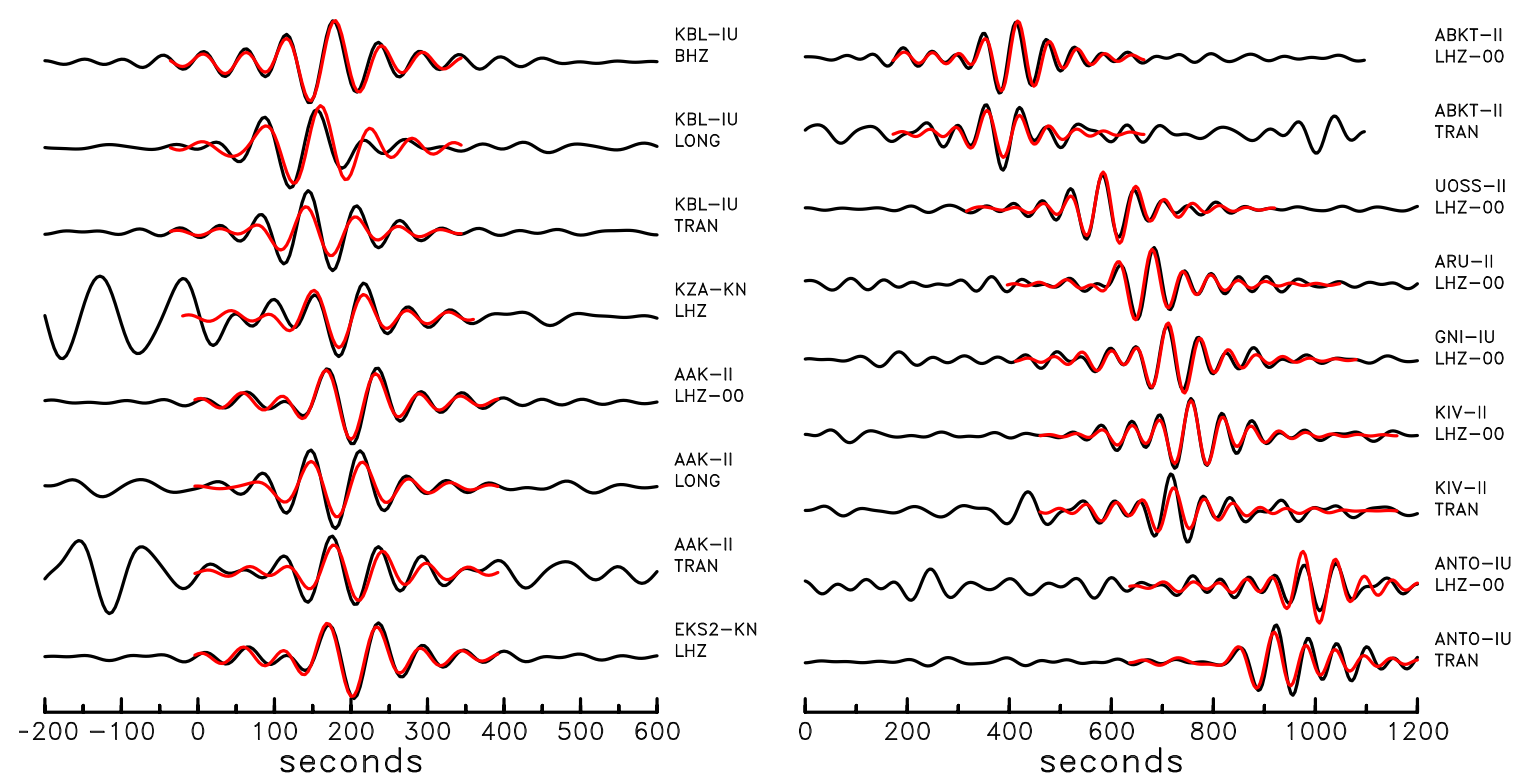

Figure S1: Comparison of observed seismograms (black) recorded at several stations of the Global Seismographic Network and the Kyrgyzstan Seismic Network and corresponding predicted waveforms (red) calculated for the best-fitting source model for the Hunza-Attabad landslide. The seismograms were filtered between $50 \mathrm{~s}$ and $150 \mathrm{~s}$ period using a phase-free (acausal) band-pass filter. The time scale (horizontal axis) is with reference to the teleseismically determined origin time of the landslide. The station and channel names are given to the right of each seismogram pair. The channel name LHZ/LHZ-00 refers to the vertical channel, and LONG and TRAN refer to longitudinal and transverse motion at the station, obtained by rotation of the horizonal seismometer channels. 


\section{Supplementary Text}

\section{Model of Slope Collapse and Acceleration}

The central model premise is that one length scale $L$ determines all the key geometric properties of the landslide source and its acceleration phase: (i) we assume that the slide geometry is self-similar $(34,35)$, that variations in the density of collapsed material are minor, and that entrainment (bulking) need not be considered, such that source mass scales with volume and thus as $m \sim L^{3}$; (ii) the angle of slope failure may vary but is assumed independent of landslide size, such that the initial height drop scales with the landslide length $H \sim L$; (iii) the travel distance downslope to the transition point between acceleration and deceleration is assumed variable but proportional to the initial height drop, and runout duration is assumed tied to acceleration duration, such that runout lasts $\Delta t \propto \sqrt{2 L / a}$. The model predicts that the peak force should scale as $F_{\max } \sim L^{3}$ and runout duration as $\Delta t \sim L^{1 / 2}$. Impulse is the integral of force over time, equivalent to $F_{\max } \Delta t$, implying that peak momentum should scales as $p_{\max } \sim L^{7 / 2}$. Similarly, the maximum speed should scale as $|\mathbf{v}|_{\max } \sim L^{1 / 2}$. Integrating the vertical force component twice suggests that the potential energy loss should scale as $\Delta E \sim L^{4}$.

\section{Constraints on volume, mass and runout distance}

Published values for landslide source volume and runout distance are available for the several of the landslides studied here (Table S1). In some cases, source mass estimates have also been published; in others, mass can be estimated given knowledge or assumption of mean source density. For most of the events analyzed here, such mass estimates were used to disambiguate the inverted, mass-scaled trajectories (Materials and Methods): Mt St Helens (6, 17, 18, 36, 37); Valpola (5, 38, 39); Kaiapit (25, 40); Randa (30,41); Yìgòng (26, 42, 43); Mt Garmo (29, 44); Mt Steller (7); Mt Steele (45); Xiăolín (27, 46, 47); Hunza-Attabad (24, 48); Mt Meager (49, 50); Akatani (28). At present there are no published constraints on the erosion volumes or runout geometry of the following events: Conchut, Rio Sócota, Sheemahant, the set of Siachen failures, Seti-Annapurna and Mt Lituya. Several seismic detections of the 2010 Typhoon Morakottriggered events (Fāngtúnshān, Fùxíng, and Táoyuán) have been published (27) but without estimates of erosion mass or runout geometry. 


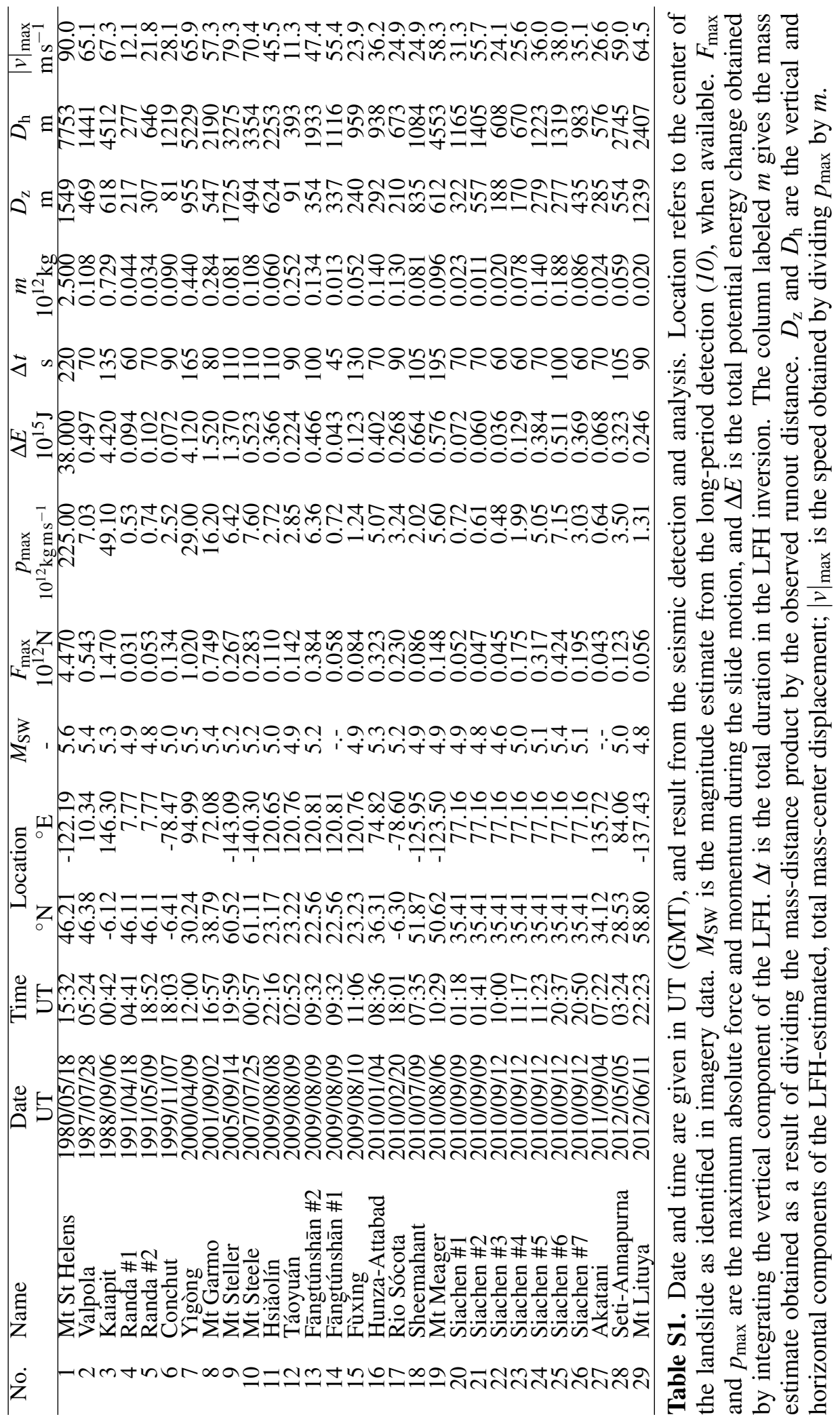




\section{References}

1. D. Weichert, R. B. Horner, S. G. Evans, Bulletin of the Seismological Society of America 84, 1523 (1994).

2. Y. Takei, M. Kumazawa, Geophysical Journal International 121, 641 (1994).

3. Y. Fukao, Geophysical Journal International 122, 243 (1995).

4. M. J. McSaveney, G. Downes, Landslides, J. Rybar, J. Stemberk, P. Wagner, eds. (Balkema, Lisse, 2002), pp. 649-654.

5. G. B. Crosta, H. Chen, C. F. Lee, Geomorphology 60, 127 (2004).

6. S. N. Ward, S. Day, Geophysical Journal International 167, 991 (2006).

7. L. Moretti, et al., Geophys. Res. Lett. 39, L16402 (2012).

8. P. Favreau, A. Mangeney, A. Lucas, G. Crosta, F. Bouchut, Geophysical Research Letters 37, L15305 (2010).

9. E. A. Okal, J. Phys. Earth 38, 445 (1990).

10. G. Ekström, Bull. Seism. Soc. Am. 96, 1201 (2006).

11. G. Ekström, M. Nettles, Global CMT catalog (2012). <http://globalcmt.org>.

12. See supplementary materials on Science Online.

13. G. Ekström, M. Nettles, G. A. Abers, Science 302, 622 (2003).

14. M. Nettles, G. Ekström, Ann. Rev. Earth Planet. Sci. 38, 467 (2010).

15. A. Shuler, G. Ekström, J. Volc. Geothermal Res. 181, 219 (2009).

16. G. Ekström, M. Nettles, A. M. Dziewonski, Phys. Earth Planet. Int. 200-201, 1 (2012).

17. H. Kanamori, J. W. Given, Journal of Geophysical Research 87, 5422 (1982).

18. H. Kanamori, J. W. Given, T. Lay, Journal of Geophysical Research 89, 1856 (1984).

19. H. S. Hasegawa, H. Kanamori, Bulletin of the Seismological Society of America 77, 1984 (1987).

20. E. E. Brodsky, E. Gordeev, H. Kanamori, Geophysical Research Letters 30, 2236 (2003).

21. M. La Rocca, et al., Bulletin of the Seismological Society of America 94, 1850 (2004). 
22. N. A. Pino, M. Ripepe, G. B. Cimini, Geophysical Research Letters 31, L02605 (2004).

23. W. G. Pariseau, Engineering Geology 16, 111 (1980).

24. D. Petley, International Water Power \& Dam Construction 63, 27(3) (2011).

25. M. Peart, Quarterly Journal of Engineering Geology 24, 399 (1991).

26. Y.-J. Shang, et al., Geomorphology 54, 225 (2003).

27. C.-H. Lin, H. Kumagai, M. Ando, T.-C. Shin, Geophysical Research Letters 37, L22309 (2010).

28. M. Yamada, Y. Matsushi, M. Chigira, J. Mori, Geophysical Research Letters 39, L13301 (2012).

29. V. M. Kotlyakov, et al., Materialy Gliatsiologicheskikh Issledovanii 95, 221 (2003).

30. E. Eberhardt, D. Stead, J. S. Coggan, International Journal of Rock Mechanics and Mining Sciences 41, 69 (2004).

31. G. Ekström, J. Tromp, E. W. F. Larson, J. Geophys. Res. 102, 8137 (1997).

32. A. M. Dziewonski, D. L. Anderson, Physics of the Earth and Planetary Interiors 25, 297 (1981).

33. A. M. Dziewonski, T.-A. Chou, J. H. Woodhouse, Journal of Geophysical Research 86, 2825 (1981).

34. N. Hovius, C. P. Stark, P. A. Allen, Geology 25, 231 (1997).

35. F. Guzzetti, F. Ardizzone, M. Cardinali, M. Rossi, D. Valigi, Earth Planet. Sci. Lett. 279, 222 (2009).

36. R. W. Burger, C. A. Langston, Journal of Geophysical Research 90, 7653 (1985).

37. B. Voight, H. Glicken, R. J. Janda, P. M. Douglass, Catastrophic rockslide-avalanche of May 18, the 1980 eruptions of Mount St. Helens (U.S. Geol. Survey, Washington D.C., 1981), vol. 1250 of U.S. Geological Survey Professional Paper, pp. 347-378.

38. G. B. Crosta, S. Imposimato, D. G. Roddeman, Natural Hazards and Earth System Sciences 3, 523 (2003).

39. G. B. Crosta, P. Frattini, N. Fusi, Journal of Geophysical Research 112, F01006 (2007).

40. M. Drechsler, I. Ripper, E. Rooke, E. Warren, Engineering Geology in Tropical Terrains, Technical sub-committee of EGITT, ed. (Universiti Kebangsaan, Malaysia, 1989), pp. 110. 
41. D. Stead, E. Eberhardt, J. S. Coggan, Engineering Geology 83, 217 (2006).

42. Z.-H. Wang, J.-T. Lu, Earth Observing Systems VII, W. L. Barnes, ed. (2002), vol. 4814 of Proceedings of SPIE, pp. 34-38.

43. C.-H. Zhou, Z.-Q. Yue, C.-F. Lee, B.-Q. Zhu, Z.-H. Wang, Quarterly Journal of Engineering Geology and Hydrogeology 34, 325 (2001).

44. D. Schneider, C. Huggel, W. Haeberli, R. Kaitna, Earth Surface Processes and Landforms 36, 1948 (2011).

45. P. S. Lipovsky, et al., Landslides 5, 445 (2008).

46. C.-Y. Kuo, et al., Journal of Geophysical Research 116, F04007 (2011).

47. C.-L. Tang, et al., Engineering Geology 106, 1 (2009).

48. J. F. J. Shroder, Geomorphology 26, 81 (1998).

49. R. H. Guthrie, et al., Natural Hazards and Earth System Sciences 12, 1277 (2012).

50. C. Huggel, J. J. Clague, O. Korup, Earth Surface Processes and Landforms 37, 77 (2012). 